\title{
APROXIMACIÓN A LAS VILLAS DE RECREO DE LA FAMILIA HEREDIA EN MÁLAGA
}

\author{
Eva María Ramos Frendo
}

\begin{abstract}
RESUMEN
El presente trabajo pretende una aproximación a la historia de tres villas de recreo del siglo XIX malagueño (San José, La Cónsula y La Concepción) que pertenecieron a miembros de una misma familia de la alta burguesía, los Heredia Livermore, y que, afortunadamente, se conservan en la actualidad, dejando muestras de una tipología arquitectónica, las residencias de relax de la oligarquía, que tuvo un gran auge en los territorios suburbanos de nuestra localidad a lo largo del periodo decimonónico y a comienzos del siglo XX. Estas páginas darán a conocer datos hasta ahora inéditos sobre las mismas y, por otro lado, ayudaran a corregir errores que hasta la fecha se han difundido sin el respaldo de la documentación que los constate.
\end{abstract}

\section{ABSTRACT}

The present work intends to make an approach on the history of the three villas in the XIXth century in Málaga (San José, La Cónsula y La Concepción). These villas belonged to the members of the same aristocratic family, the Heredia Livermore, and are still preserved as a model of the architectonic style referred to the villas used by the oligarchy in Málaga during the XIXth century and the beginning of the XXth. We'll know, throughout this study, unpublished data above them, and we'll be able to correct investigation mistakes published without any documents that guarantee them.

\section{BREVE COMENTARIO SOBRE EL ORIGEN Y EVOLUCIÓN DE LAS VILLAS}

La villa es una residencia ubicada en el campo, compuesta de una vivienda para el propietario, junto con otra serie de dependencias, normalmente más ligadas a la actividad de explotación agrícola, además de todo un entorno natural que la rodea. En ella, el ciudadano, normalmente enriquecido por la industria y el comercio urbano, puede alejarse del bullicio de la ciudad y dedicarse al descanso, las relaciones sociales, la reflexión y a disfrutar de la salud $\mathrm{y}$ vistas que proporcionan dichos parajes. 
Esta tipología fue creada por los patricios en la antigua Roma y muchos han sido los testimonios de aquella época que dejaban constancia de los beneficios de este tipo de residencias ${ }^{1}$. Normalmente comprendía dos espacios claramente diferenciados, la parte urbana, que sería el lugar de residencia del propietario, y la parte rústica, donde se encontrarían los espacios de labor, almacenes, cocinas y vivienda de los empleados.

El primer espacio, en un principio de carácter más secundario, dado que el propietario tan sólo realizaba visitas rápidas a la villa para supervisar las cuentas y el estado de sus propiedades, fue más adelante desarrollándose y adquiriendo todo tipo de comodidades hasta adquirir el papel más destacado dentro de la villa, hasta el punto que, en muchos casos, desaparecía totalmente la zona anteriormente denominada rústica, donde se concentraban las labores de explotación agrícola y manufacturas, y la villa se convertía exclusivamente en un lugar de retiro y relax para el dueño de la misma.

Además, la búsqueda del ocio y disfrute del entorno donde se ubicaban estas villas produjo una transformación en la residencia, desde un modelo más cerrado que seguía el ejemplo de las viviendas urbanas hacia formas cada vez más abiertas, para poder fundirse con la naturaleza que las envolvía. A su vez, los interiores de la vivienda se poblaron de pinturas al fresco donde igualmente los paisajes eran las temáticas preferidas y mosaicos que cubría los pavimentos.

Desde entonces esta tipología se ha desarrollado, con ciertas variantes, a lo largo de toda la historia y siempre ligada a las clases más poderosas, puesto que la posesión de una villa de recreo es claramente un prestigio que sólo los más pudientes se pueden permitir. Unicamente, entre los siglos $\mathrm{V}$ a XIII, la inestabilidad y falta de seguridad hizo que las mismas desaparecieran, resurgiendo de nuevo en el siglo XIV en Florencia, sobre todo ligadas a la familia Medici, y presentando estilos que evolucionarán desde formas medievalizantes muy fortificadas a modelos más abiertos y en estilos clasicistas, pero en ambos casos siempre rodeadas de espléndidos jardines. A partir de dicha centuria, las villas fueron extendiéndose tanto en el tiempo como el espacio, siendo siempre un claro símbolo de poder y prestigio, a la vez que un espacio para el descanso y la huida de la ciudad de los más poderosos, en ocasiones el lugar ideal para recuperarse de alguna enfermedad o tragedia familiar².

1. El poeta Horacio, el senador y escritor Plinio el Joven o el también poeta Marcial entre otros.

2. Sobre la villa a lo largo de la historia cfr. ACKERMAN, J.: La Villa. Forma e ideología de las casas de campo, Madrid 1997. 


\section{LAS VILLAS DE RECREO DE LA BURGUESÍA MALAGUEÑA DEL SIGLO XIX}

Málaga, como muchos historiadores nos han relatado, tuvo, a partir de la tercera década del siglo XIX, uno de sus momentos de mayor esplendor ${ }^{3}$. Se produjo la reactivación de su comercio ${ }^{4}$, basado especialmente en el intercambio de sus productos agrícolas con los mercados de Europa y América del Norte a través de su puerto ${ }^{5}$, actividad que, unida al contrabando a través de Gibraltar de comienzos del siglo XIX, propició la acumulación de capitales que serían invertidos en el despegue de su industria, sobresaliendo principalmente los sectores de la siderurgia y la rama textil.

En todo este proceso destacaron una serie de familias (extranjeras y españolas) que tenían en común su origen foráneo de la capital malagueña ${ }^{6}$ y que atraídos por la prosperidad de la misma y, en algunos casos, huyendo de situaciones de crisis de sus lugares de origen (caso de muchos de los cameranos y riojanos $^{7}$ ) se afincaron en nuestra ciudad y pasaron a convertirse en los grupos de elite de la misma.

3. LACOMBA, J. A.: "Málaga 1833: la frontera entre dos épocas", Jábega 8, 1974, 36-40; Idem: Crecimiento y crisis de la economía malagueña, Málaga 1987; Idem: Sociedad y política en Málaga en la primera mitad del siglo XIX, Málaga 1989; MORALES MUÑOZ, M.: Economía y sociedad en la Málaga del siglo XIX, Málaga 1983; NADAL, J.: "Orígenes de la industrialización en España: Málaga”, España Económica, Madrid 1969.

4. En la segunda mitad del siglo XVIII, especialmente a partir del decreto promulgado por Carlos III en 1778 que otorgó la libertad de comercialización con América, Málaga se verá favorecida con una importante actividad comercial basada, sobre todo, en la exportación de sus productos agrícolas (vino, uvas, pasas, aceitunas, aceite y, en menor medida, limones, naranjas, higos, almendras, etc.) a cambio de la importación de productos alimenticios básicos, como los cereales. Cfr. LACOMBA, J. A.: "Málaga a finales del siglo XVIII: una ciudad próspera", Jábega 2, 1973, 60-4. Tras esta etapa floreciente, en 1796 entramos en una época crítica, motivada por la guerra con Gran Bretaña que provocó la paralización de las actividades comerciales y seguida por la ocupación francesa y sus graves consecuencias, además de otras muchas calamidades (epidemias, hambrunas, terremotos, inundaciones, etc.) que agravaron aún más la realidad del momento, hasta que en la fecha citada se vuelve a recuperar el timón de la ciudad.

5. VILLAR GARCÍA, B. y MARTÍNEZ MOUTON, M.: "Los extranjeros en Málaga a mediados del siglo XIX”, en GARCÍA MONTORO, C. (coord.): Sociedad y negocios en Málaga (Siglos XVIII-XIX), Málaga 1998, 110.

6. Sobre los extranjeros en Málaga cfr. BURGOS MADROÑEROS, M.: "Málaga siglos XVIIIXIX: los extranjeros”, Jábega 7, 1974, 49-52; GÁMEZ AMIÁN, A.: Comercio colonial y burguesía mercantil "malagueña” (1765-1830), Málaga 1992; VILLAR GARCÍA, M. B.: Los extranjeros en Málaga en el siglo XVIII, Córdoba 1982.

7. GARCÍA MONTORO, C.: Málaga en los comienzos de la industrialización: Manuel Agustín Heredia (1786-1846), Córdoba 1978, 17. 
Como consecuencia del fenómeno de zonificación de la época, esta pujante burguesía se concentro en una misma zona, la Alameda malagueña o sus proximidades $^{8}$, espacio situado fuera del casco antiguo, en unos terrenos ganados al mar, donde se produjo a finales del siglo XVIII un proceso de urbanización a través de un trazado ortogonal con calles amplias y rectas que se dotaron de zonas verdes, por medio de una alineación geométrica de álamos, siguiendo el modelo de los salones o paseos arbolados de la época. Se generó así un espacio lúdico y saludable que sería el escogido por este nuevo grupo social para edificar sus residencias.

Pero, como es normal en todo grupo privilegiado que se precie, además de la vivienda urbana y algunas otras propiedades inmobiliarias, contarían con una o más residencias fuera de la ciudad, destinadas a su descanso y recreo en los meses de verano o durante los fines de semana, la denominada villa suburbana o finca de recreo ${ }^{9}$, donde se alejaban del trabajo diario, para disfrutar de sus momentos de ocio. Algo que durante el resto de la historia había sido signo distintivo de los patricios romanos, los ricos señores o la nobleza y, en esos momentos, era lo habitual entre la alta burguesía de toda Europa. Estos espacios fueron testigo de numerosas fiestas, meriendas, veladas, excursiones, etc., realizadas al aire libre, siempre que el tiempo lo permitiera, para gozar de las numerosas sensaciones que proporcionaban sus bellos jardines.

En Málaga, las zonas preferidas para crear estos espacios de ocio fueron Churriana, Torremolinos y la zona por donde hoy discurre la carretera de las Pedrizas, lugares donde se disfrutaba de un buen clima, principal distintivo de nuestra localidad, y que, además, se encontraban a una adecuada distancia del núcleo urbano.

En la actualidad la gran mayoría de estas villas o casas de recreo han desaparecido, siendo tan sólo la documentación o prensa de la época la que nos puede aportar algunos datos sobre ellas. Así, por ejemplo, sabemos que en Torremolinos se encontró la casa de recreo de la familia Rein ${ }^{10}$ o la del alcalde Liborio García ${ }^{11}$, mientras en Churriana, al oeste de la ciudad de Málaga, se concentraron otras muchas villas: San Javier, propiedad de Don Manuel Piedrola Blake y doña Petra Abadia Hoppe ${ }^{12}$, Santa Tecla, El Platero de

8. GARCÍA GÓMEZ, F.: "La Alameda de Málaga y el Salón del Prado. Estudio Comparativo", Baetica 15, 1993, 7-19; Idem, Los orígenes del urbanismo moderno en Málaga: el Paseo de la Alameda, Málaga 1995.

9. GARCÍA GÓMEZ, F.: La vivienda malagueña del siglo XIX. Arquitectura y sociedad, Málaga 2000, Tomo I, 726-44.

10. (A)rchivo (H)istórico (P)rovincial de (M)álaga: 1884, leg. 5395, Partición a bienes de don Guillermo Rein Nagel, fol. 4876.

11. PADRÓN RUIZ, J. M.: Málaga en nuestros días, Málaga 1896, 108-9.

12. A.H.P.M.: 1883, leg. 5475, Partición por fallecimiento de don Manuel Piedrola Blake, fols. $1520-1528$. 
Juan Larios y Enríquez, Marqués de Valle Umbroso ${ }^{13}$, Monsalve, el Cortijo de Crucet, de don Eduardo Huelin Reissig y doña Amalia Sans Crucet ${ }^{14}$, Santa Amalia, perteneciente a don José Pastor Marra y doña Amalia Delius Rein ${ }^{15}$ o la hacienda de Martín Heredia (lugar donde se hallaron numerosos restos arqueológicos de época romana) ${ }^{16}$.

Pero, afortunadamente, se conservan algunos ejemplos notables por la belleza tanto de sus edificios como de los entornos que los rodean, que tuvieron un papel destacado en la vida malagueña del siglo XIX y además, curiosamente, pertenecieron a miembros de una misma familia. Nos referimos a las villas de recreo de la familia Heredia Livermore, cuya historia, en algunos casos, es sobradamente conocida, mientras en otros la falta de fuentes documentales aportadas hasta la fecha han llevado a un desconocimiento de su historia o a difundir noticias erróneas y sin fundamento sobre las mismas.

\section{LAS VILLAS DE RECREO DE LA FAMILIA HEREDIA}

Cuando hablamos de la familia Heredia nos referimos a los hijos de don Manuel Agustín Heredia ${ }^{17}$, principal responsable del desarrollo industrial de la ciudad de Málaga, y de doña Isabel Livermore Salas. Tres hijos de Manuel Agustín Heredia fueron propietarios de sendas villas de recreo que en la actualidad son algunos de los pocos ejemplos que nos quedan de esta tipología. Por una lado, en el comienzo de la carretera de las Pedrizas persisten La Concepción y San José, ubicadas ambas en el partido del Guadalmedina, que pertenecieron a Amalia Heredia Livermore y a su esposo, Jorge Enrique Loring Oyarzabal, Marqueses de Casa-Loring, y a Tomás Heredia Livermore, respectivamente, mientras que en Churriana se conserva La Cónsula, que tras pasar por otras manos, también sería adquirida por otro Heredia, Enrique Heredia Livermore.

13. PADRÓN RUIZ, J. M.: Málaga en...op. cit., 106-7

14. A.H.P.M.: 1885, leg. 5400, Inventario de bienes de don Eduardo Huelin Reissig, fols. 4776$4778 \mathrm{v}$.

15. A.H.P.M.: 1887, leg. 5589, Testamento de doña Amalia Delius Rein, fols. 4126-4132.

16. RAMOS FRENDO, E.: "El gusto por las antigüedades en Málaga durante el siglo XIX", Actas del Congreso La Tradición Clásica en Málaga (s. XVI-XXI), Málaga 2005, 139-150.

17. GARCÍA MONTORO, C.: La personalidad y la obra de Manuel Agustín Heredia (17861846), Granada 1976; Idem, Málaga en los comienzos...op. cit. 


\subsection{La Concepción}

La historia de la hacienda de La Concepción ha sido la más conocida y difundida de las tres villas citadas ${ }^{18}$. Fue adquirida, entre abril y diciembre de 1857, por el matrimonio formado por Jorge Enrique Loring Oyarzabal ${ }^{19}$ (1822-1900), destacado comerciante malagueño, y Amalia Heredia Livermo$\mathrm{re}^{20}$ (1830-1902), Marqueses de Casa-Loring a don Manuel Gutiérrez y otros propietarios $^{21}$, tras haber pasado durante siglo y medio por diversas manos ${ }^{22}$. El precio de compra fue de 72.000 reales, es decir unas 24.000 pesetas, valor no muy elevado si tenemos en cuenta que hacia el año 1847 las tres haciendas rústicas de su padre, Manuel Agustín Heredia (Don Timoteo, San José y San Luis), ubicadas en el partido de Chapera, se tasaban en 200.000, 150.000 y 128.376 reales de vellón respectivamente. Esto nos hace pensar que, por aquel entonces, La Concepción no tendría nada que ver con la lujosa y paradisiaca villa en la que se convertiría posteriormente, gracias al incansable trabajo y amor de sus dos nuevos propietarios que se encargaron, parece ser, de construir el bello palacete de estilo clasicista que alberga y de diseñar los jardines tropicales que la rodean y que son su principal atractivo turístico en la actualidad

De manera que los estudios realizados sobre la misma hasta la fecha han permitido acabar con el gran error que durante muchos años se ha difundido y que insistía en que dicha hacienda había formado parte con anterioridad de su vecina San José, villa que consideraban propiedad de don Manuel Agustín Heredia (nuevo error que veremos subsanado al hablar de la citada hacienda), y que en 1850 dicho caballero seccionaría un trozo de sus terrenos (la futura finca de La Concepción) para regalarlos en dote a su hija Amalia que contraía, en mayo de dicho año, matrimonio con Jorge Enrique Loring Oyarzabal. Una

18. Sobre La Concepción cfr. CAÑIZO PERATE, J. A. del y LASSO DE LA VEGA WESTENDORP, B.: Jardín Botánico-Histórico La Concepción, Málaga 1996; MUÑOZ MARTÍN, M.: "Vicisitudes Históricas de la Hacienda de La Concepción", Isla de Arriarán XI, 1998, 319-26 y GARCÍA GÓMEZ, F.: La Concepción. Testigo del tiempo, Málaga 2004.

19. Sobre este destacado malagueño cfr. CAMPOS ROJAS, M. V.: "Jorge Enrique Loring Oyarzabal: primer Marqués de Casa-Loring (1822-1900)", Jábega 58, 32-38.

20. Cfr. RAMOS FRENDO, E. M.: Amalia Heredia Livermore, Marquesa de Casa-Loring, Málaga 2000.

21. Información obtenida en OLMEDO CHECA, M.: "Introducción" en RODRÍGUEZ DE BERLANGA, M. (1864): Monumentos Históricos del Municipio Flavio Malacitano, Málaga 2000, Edición Facsímil, 61.

22. MUÑOZ MARTÍN, M.: "Vicisitudes Históricas de la Hacienda de La Concepción", Isla de Arriarán XI, 1998, 319-26. 
historia que es totalmente falsa, dado que ni en dicha escritura de dote, ni en la herencia de su padre aparece reflejada ninguna finca o hacienda rústica ${ }^{23}$ y, además, imposible, dado que en la fecha que se fija el regalo su padre ya llevaba cuatro años fallecido.

Posteriormente, la finca se amplió con nuevos terrenos procedentes de las haciendas Cantero y Mininos ${ }^{24}$ y más tarde con otras para el paso de las aguas de la finca llamada Hoyo.

Así pues, el matrimonio Loring y, sobre todo, de manera especial y más directa, Amalia Heredia Livermore, Marquesa de Casa-Loring, serían los responsables de este entorno que, afortunadamente, hoy día podemos disfrutar. Un jardín encuadrado dentro del estilo paisajístico y en la estética de los pintoresco, originada en Inglaterra y desde allí difundido por el resto de occidente, donde la naturaleza se libera del orden y geometrismo de épocas anteriores (Renacimiento y Barroco) y se presenta libre e irregular, surcada por caminos serpenteantes, terrenos en desnivel, cascadas, miradores y templetes, con la singularidad, en este caso, de presentar especies tropicales perfectamente aclimatadas ${ }^{25}$.

Pero, como ya veíamos desde la época de los romanos, esta finca contó con dos zonas: una la parte de recreo y otra la de huerta, donde se ubicaba además una edificación destinada a residencia del administrador y demás empleados de la hacienda. No obstante, la explotación de estos terrenos tenía una función secundaria, dado que con lo que de ellos se obtenía no se tenía para sufragar los gastos que la villa, lo que nos indica que la posesión de la misma no tenía nada que ver con motivos económicos. La misma Amalia indicaría en uno de sus testamentos: - "...temo que no lleguen nunca a cubrir los productos los gastos de entretenimiento..."

También este matrimonio fue el responsable de las diversas edificaciones que podemos hallar en la finca. Por una lado, la gran mansión donde los mismos residirían durante largas temporadas, recibiendo en su interior a lo más selecto de la alta burguesía malagueña y a importantes personajes, sobre todo de la política, de la época ${ }^{27}$, además del templete clásico que sirvió de albergue

23. RAMOS FRENDO, E. M.: Amalia Heredia Livermore...op. cit., 188-93.

24. A.H.P.M.: 1857 , leg. 4544 , fol. $2113 \mathrm{v}$. -2117.

25. Sobre las especies botánicas de La Concepción cfr. CAÑIZO, J. A. del: Jardines de Málaga, Málaga 1990, 63-78 y CAÑIZO PERATE, J. A. del y LASSO DE LA VEGA WESTENDORP, B.: Jardín Botánico-Histórico..op. cit., 34-41.

26. A.H.P.M.: Francisco Villarejo González, 1902, leg. 6054, Testamento de Amalia Heredia Livermore de 1896, fol. 5771v.

27. Sobre las actividades y acontecimientos que tuvieron lugar en esta hacienda cfr. RAMOS FRENDO, E. M.: Amalia Heredia....op. cit., especialmente en las páginas 71-5, 81-93 y 97-8. 
a la mayor parte de piezas de la colección arqueológica ${ }^{28}$, que el matrimonio creó y alojó en este paraje, o la pérgola envuelta en glicinas que servía para un agradable relax. El palacete se decoró con gran lujo y esplendor, cuajándose sus paredes de obras de arte, mobiliario de gran calidad y platería. Además, su biblioteca se convirtió, por los fondos que custodiaba, en una de las más apreciadas de la época.

Esta villa, como se puede observar por las propias palabras de su propietaria, no fue sólo un lugar de descanso. Según expresaba en carta que dirigía a don Juan Blasco Barroso en 1893: "Desde aquí me sirve también La Concepción de mi mayor recreo, porque más que con nada gozo pensando en aquel delicioso rincón" 29 .

Pocos años antes del fallecimiento de sus propietarios la finca se encontraba hipotecada al Marqués de Vallejo y se valoraba en 100.000 pesetas. El mayor deseo de los marqueses era que la misma permaneciera en la familia, pasando a manos de su yerno el político Francisco Silvela ${ }^{30}$ y de sus hijas Amalia, esposa de éste, e Isabel, viuda del Conde de Benahavis, Ricardo Heredia Livermore, mas esto fue algo que pudo lograrse sólo hasta el año 1911, momento en el que La Concepción pasó a poder del matrimonio vasco Echevarría Echevarrieta y dejó de pertenecer a la familia Heredia.

\subsection{San José}

Como ya adelantábamos previamente, San José no fue en ningún momento propiedad de Manuel Agustín Heredia Martínez, dado que dicha hacienda se encontraba en el partido rural de Guadalmedina y la que poseyera Manuel Agustín Heredia se encontraba en el partido de Chapera, por lo que eran fincas diferentes, aunque poseyeran idéntico nombre.

\subsubsection{Historia anterior a la adquisición de Tomás Heredia Livermore}

Hasta 1761, esta hacienda llamada en aquel entonces Nadales estuvo en poder de doña Ana Natera, viuda de don Miguel Ordoñez, y de dos de sus hijos, Juan y María Ordoñez Natera. Todos ellos se verían obligados a venderla a su hijo y hermano respectivamente José Ordoñez Natera, para con los resultados de dicha operación poder subsanar deudas. Al fallecer, en julio de 1788, este último propietario, la hacienda pasó a su viuda $\mathrm{M}^{\mathrm{a}}$ de los Dolores

28. RODRÍGUEZ DE BERLANGA, M.: Catálogo del Museo Loringiano, Málaga 1903.

29. Cartas aportadas en OLMEDO CHECA, M.: "Introducción...op. cit.", 63.

30. A.H.P.M.: 1902, leg. 6054, Testamento de Amalia Heredia Livermore de 1896, fols. 57715772v. y Testamento de Amalia Heredia Livermore de 1898, fols. 5773-5774v. 
Bustillos, estando valorada hacia el año 1803 en 214.415 reales (unas 72.000 pesetas). Ésta, a su vez, la legó al año siguiente, 1804, a su hijo Fernando Ordoñez Bustillos (por esas fechas también se la conocía ya como Hacienda San José) quien la tuvo en su poder hasta su fallecimiento en 1838.

En 1843 se realizaría la partición de sus bienes y la hacienda, en esos momentos, constaba de 80 y media fanegas de tierra que comprendían viñas, casa lagar, vasija, molino de aceite, huerta, limonar, olivar, casas de recreo, cochera, oratorio, palomar, alcubilla, cañería, cercas, paredones, albercas y un gran depósito o alberca en construcción, apreciándose todo en 1.370.016 reales (unas 456.672 pesetas) ${ }^{31}$. No se nos indica la existencia de jardines en torno a la casa de recreo.

Doña Manuela Viana, viuda de don Fernando Ordoñez Bustillos, recibió la mitad de la hacienda a la que, para regularizar sus linderos, le segregó un pedazo a cambio de otra porción de terrenos de la Hacienda de León o Leoncillo. La otra mitad se repartió entre sus cinco hijos: María Dolores, Antonia, José, María Victoria y Melchor Ordoñez Viana.

Al morir Doña Manuela Viana, en 1852, la hacienda pasó a poder de sus hijos y nietos. Se inician, a partir de ese momento, toda una serie de segregaciones de terrenos o traspasos ${ }^{32}$.

\subsubsection{La Hacienda de San José en poder de los Heredia}

Finalmente, en 1864, tras el fallecimiento de algunos de los propietarios anteriores, la hacienda se encontraba en poder de don José Ordoñez Viana, de su cuñado don Enrique Roose Warusch (viudo de $\mathrm{M}^{\mathrm{a}}$ Victoria Ordoñez Viana) y los hijos de éste último, Juan, Rafaela (conocida pintora malagueña), Enrique y Victoria Roose Ordoñez.

Todos estos venderían, el 13 de mayo de 1864, a don Tomás Heredia Livermore la parte que poseían de la Hacienda conocida como San José, Nadales o también, después de tanto tiempo en manos de una misma familia, Hacienda de Ordoñez (la 64 centésimas y tres cuartos de la misma). En esos momentos la finca constaba de 39 hectáreas, 54 áreas, 23 centiáreas y 50 decímetros cuadrados y contenía un limonar, viña, huerta, arboleda, tierras calmas y mandrón, casas principal y de labor, lagar de pisar con bodega, molineta y demás dependencias, cañerías, alcubillas, oratorio, cerca y portada.

31. Un gran valor, si tenemos en cuenta que la del mismo nombre que poseía Manuel Agustín Heredia por esas fechas se apreciaba e 150.000 reales.

32. Toda la historia de la hacienda hasta su venta a don Tomás Heredia Livermore se encuentra en A.H.P.M.: 1864, leg. 4696, Venta. El Excmo. Señor don Tomás Heredia contra don José Ordoñez y Viana, don Enrique Roose Warusch, Consul General de Prusia, don Juan, Rafael, Enrique, $M^{\mathrm{a}}$ Victoria Roose Ordoñez, fols. 1115-1166v. 
Dos años más tarde, el 23 de febrero de 1866, la hacienda se amplio con el resto de los terrenos que faltaban de la misma (las 35 centésimas y un cuarto de la totalidad de la hacienda) que fueron adquiridos a doña Rosalía Ortega Ortega.

A su vez, don Tomás Heredia amplió la mencionada propiedad con nuevos terrenos de la hacienda de Leoncillo o León el bajo y con un trozo de limonar conocido por el Cañaón, que antiguamente había pertenecido a la hacienda de San José, adquiridos a miembros de la familia Sostoa Ordoñez (Rafael, Victoria, Enrique, Trinidad, Manuel, Tomás y $\mathrm{M}^{\mathrm{a}}$ de la Concepción) y a don Manuel García de Segovia y Brias. Con esta nueva compra la propiedad aumento en 46 hectáreas ${ }^{33}$ y sólo tres meses después volvería a añadir 16 hectáreas más.

Tras todas estas ampliaciones la hacienda pasó a contar con 53 hectáreas, 23 áreas y 28 centiáreas y, hacia 1902, se valoraba en 250.000 pesetas ${ }^{34}$. Con anterioridad a que Tomás Heredia adquiriera San José se nos hablaba de la existencia en la misma de casas de recreo, mas no podemos conocer si entre dichas construcciones se encontraba el palacete actual. Sin embargo, en la partición de bienes de Tomás Heredia Livermore sí se remarca la existencia en esta finca de una "villa o casa principal de primer orden" 35 , lo que nos indica la calidad de la misma. Dicho palacete debió ornamentarse con gran número de obras de arte, dado que, como demostró en la Exposición de 1874, Tomás Heredia poseía gran número de cuadros de gran valor y de escuelas muy diversas (española, italiana, flamenca, francesa y alemana), junto con escultura, mobiliario y otros destacados objetos ${ }^{36}$. Igualmente, el inventario de bienes de Tomás Heredia nos indica la riqueza de los enseres que decoraban sus viviendas, dado que los muebles y cuadros, junto con los carruajes y caballos que poseía en sus residencias de Málaga y Carratraca ascendían a 40.000 pesetas, un valor bastante elevado para la época. Del mismo modo, las palabras de Blasco Alarcón son otra clara muestra del lujo con que los Heredia amueblaban sus residencias ya que, como nos expresa cuando se vendió San José, entre los embalajes encontraron el último pedido que dicha familia había realizado a la Casa Maple. Allí se pudieron hallar "verdaderas maravillas de muebles ingleses de la mayor elegancia y lujo, superior su precio al pagado por la finca" ${ }^{37}$.

33. Estas ampliaciones se realizan por escrituras otorgadas el 28 de mayo de 1865, el 15 de noviembre de 1867 y el 22 de mayo de 1868 ante don Manuel Romero de la Bandera.

34. 150.000 pesetas más que la de su hermana Amalia Heredia.

35. A.H.P.M.: 1902, leg. 6047, Partición a bienes de don Tomás Heredia Livermore, fol. $1974 \mathrm{v}$.

36. Catálogo de la Exposición Retrospectiva celebrada por el Liceo de Málaga en el mes de junio de 1874, Málaga 1874, 18-9, 21-2, 26-7, 32-5 y 37-42.

37. BLASCO ALARCÓN, M.: La Málaga de comienzos de siglo, Málaga 1973, 16-7. 
Además, San José contó con una granja o casa de labor, que también se especificaba que era de primer orden, junto con otra de menor importancia, una portería y verja de entrada de primer orden y otras de segundo y tercero, un invernadero de primer orden, que aún hoy se conserva, junto con otros seis menos destacados, cuatro estanques o albercas, un lago, varias grutas con cascadas, dos fuentes, gallinero y lavadero.

Junto con todas estas construcciones ya sí se nos especifica la existencia de jardines que rodeaban la casa principal, las actuales especies tropicales que se disponen con un estilo paisajístico igual al ya citado en La Concepción, donde se insertan algunos de los elementos citados anteriormente (lago, grutas con cascada, fuentes, invernaderos). Junto a estos jardines se disponía una importante extensión de terreno dedicado a huerta. Entre los árboles y arbustos se citaban frutales, álamos, limoneros, olivos, algarrobos, almendros y alguna $v_{\text {viña }}{ }^{38}$. Del mismo modo que su hermana, Tomás también poseyó restos arqueológicos (una pequeña muestra en comparación con lo que tuviera Amalia) que se encontraron dispersos por los jardines ${ }^{39}$.

\subsection{La Cónsula}

\subsubsection{Historia anterior a la adquisición de Enrique Heredia Livermore}

La Hacienda de San Rafael, ubicada en las proximidades del pueblo de Churriana, fue, durante el siglo XVIII, simplemente una explotación agrícola. Perteneció, primeramente, a un presbítero, don Pedro Ponce, y de él pasaría, en 1733, a su hermana y más tarde, en 1754, a los hijos que la misma había tenido de su segundo matrimonio con don Andrés de Alarcón.

En 1787 y buscándose sobre todo el solventar deudas y acreedores, las diversas partes en que se había dividido la hacienda fueron vendidas a otra familia, la compuesta por don Pedro López, presbítero de la villa de Cártama, y su hermana doña María, en la cantidad de 100.000 reales. Durante el tiempo que la huerta estuvo en poder de este presbítero y de su hermana debió realizarse el templete cupulado que actualmente podemos contemplar en la finca y que denominan Tumba del cura, aunque en el siglo XIX lo llamaban La Gruta. Esta obra recrea en su interior una gruta artificial, posee poyos de obra y en el intradós de la cúpula, revestida de conchas, del mismo modo que las escaleras que conducen a este lugar, presenta en su tambor la cruz y la plegaria AVE

38. Ibidem, fols. 1974v.-1975v.

39. BAENA ALCAZAR, L.: "La colección de antigüedades romanas de la finca de San José (Málaga)", Mainake X, 137-50. 
MARIA $^{40}$. Es, concretamente, el año 178.. que podemos leer incompleto en los cascos de la bóveda lo que nos indica que sería el citado don Pedro López el promotor de esta construcción.

Al fallecer ambos hermanos, la existencia de diversos acreedores obligó a subastar la citada huerta de Churriana para solventar las deudas. Fue entonces cuando don Juan Roose, Cónsul de Prusia, aparece en la historia de esta hacienda. Dicho señor se ofreció a pagar no solo el valor de la huerta sino además la cantidad necesaria para el pago de los diversos créditos que la aquejaban.

Aprobada la oferta, el 4 de febrero de 1802, por el tribunal de la Chancillería de Granada, la huerta salió a subasta el 1 de marzo de ese mismo año, rematándose en la cantidad de 142.000 reales que fueron pagados por don Ambrosio Cuartero, como intermediario de don Juan Roose, quien a continuación cedió la huerta a dicho señor. Finalmente, el 8 de junio de 1804 se celebró la escritura de venta de la citada huerta a favor de don Juan Roose.

\subsubsection{De hacienda a villa de recreo: la familia Roose}

Don Juan Roose Kupckovius, nacido en una localidad cercana a Berlín, en lo que entonces era Prusia ${ }^{41}$, emigró a España a finales del siglo XIX. Se afincó en la ciudad de Málaga, posiblemente atraído por la prosperidad comercial de esos momentos, al igual que otros muchos extranjeros, y en dicha localidad ostentó el cargo de Cónsul de su país de origen y, además, fundó la casa de comercio Lambrecht, Roose y Compañía, dedicada a la exportación de vinos. Esta compañía, de la que fue socio único, mantuvo relaciones comerciales con Génova, Gibraltar, Hamburgo, San Petesburgo y Dinamarca.

Juan Roose contrajo matrimonio el 17 de febrero de 1793 con doña Rafaela Warusch Velasco, natural de Málaga. ${ }^{42} \mathrm{Al}$ igual que el resto de los miembros de la alta burguesía, don Juan Roose deseó contar con una casa de recreo donde alejarse del bullicio de la ciudad y descansar durante el tiempo de ocio. Así que aprovechó la subasta de la hacienda de San Rafael para hacerse con unos terrenos en los que materializar su villa, terreno que a su

40. CAMACHO MARTÍNEZ, R.: "El jardín barroco en Málaga. "El Retiro", de Churriana", Isla de Arriarán XIX, 2002, 120.

41. A.H.P.M.: Escribanía de don Francisco María Piñón, leg. 4053, 1839, Escritura de Dote de Juan Roose y Rafaela Warusch y aumento de dote, fols. 423v.-446.

42. A.H.P.M.: Escribanía de don Francisco $M^{a}$ Piñón, 1839, leg. 4053, Liquidación, cuenta y partición a los bienes y efectos quedados por muerte de Don Juan Roose y Kupckovius, fols. 416-417v. y Escribanía de don Francisco Ma Piñón, leg. 4065, 1850, Liquidación, cuenta y partición de los bienes y efectos quedados por muerte de doña Rafaela Warusch, fol. 1024. 
vez amplió un año después con seis fanegas de tierras ubicadas en el lugar denominado el Palmar y compradas al Ayuntamiento de Málaga por valor de 600 reales $^{43}$.

En 1807, don Juan Roose inició la construcción de una casa de recreo y la adornó con plantaciones, fuentes y otra serie de mejoras. Por lo tanto, debe ser de esta época el palacete clasicista que en la actualidad observamos en dicha hacienda e igualmente, el jardín principal que se encuentra ante la mansión de estilo similar al clasicista francés por lo racional de su diseño y por el uso de los parterres, que podría tratarse de aquel cuyo diseño se decía que le había sido dado a don Juan Roose por el Conde de Villalcázar, propietario de la vecina hacienda de El Retiro $^{44}$.

Dicho jardín, ubicado delante de la casa principal, consta de una rotonda de mármol rodeada de jarrones, centrada por una fuentecilla que presenta un niño montado sobre un pato de claro estilo dieciochesco. Además, de forma similar a sus vecinos jardines de El Retiro, presenta escaleras revestidas de conchas y estalactitas y caminos flanqueados de jarrones de cerámica, junto con otras fuentes y surtidores.

El palacete es una construcción de autor desconocido ${ }^{45}$ que recuerda a las coloniales que se crearon en las haciendas Sudamericanas y del Sur de Estados Unidos. Presenta una planta rectangular, con dos pisos y patio interior, que en el exterior, en tres de sus lados, se abre con galerías de arcos carpaneles sobre columnas toscanas de mármol blanco, dispuestas sobre pedestales, que en la planta superior presentan antepechos con rejería. Dichas galerías se rematan en el segundo piso con una balaustrada con machones coronados con jarrones, tras la que se esconde la cubierta de tejas morunas. Los ángulos del edificio poseen unos pilares con columnas adosadas ${ }^{46}$. Esta edificación, con esa apertura en su estructura, consigue una perfecta comunión entre vivienda y jardín, haciendo que sus residentes pudieran disfrutar de las vistas y de la simbiosis con el ambiente natural que les rodeaba.

43. A.H.P.M.: Escribanía de don Antonio del Castillo Fragua, 1805, leg. 3497, Compra de don Juan Roose al Ayuntamiento de Málaga.

44. A.M.S.(1814): Descripción de la casa de campo del Retiro del Conde de Villalcazar, Málaga, 20. Textualmente nos indica: A la derecha el mar, Churriana y la bella casa del cónsul de Prusia D. Juan Roz (Roose), á quien el conde Villalcázar estimaba mucho, y le dio el plan de un gracioso aunque pequeño jardin.

45. Examinado el legajo 3564 del año 1807, perteneciente a don Francisco María Piñón, notario de la familia Roose, no encontramos documentación que recoja datos sobre la construcción de la casa de recreo.

46. GARCÍA GÓMEZ, F. J. y SALVO RABASCO. E.: "Hacienda "La Cónsula", en SAURET GUERRERO, T. (Dir): Patrimonio Cultural de Málaga y su provincia, Málaga 1999, Tomo I, 80-3. 
En 1824, la hacienda fue nuevamente ampliada con otras tierras ubicadas a la entrada de la misma, "un pedaso como de tres cuartillas" ${ }^{47}$, según nos indica la documentación, que formaban parte del Cortijo llamado del Veedor o de San Javier, propiedad de don Francisco Javier Abadía, quien las donó a don Juan Roose y a su esposa, doña Rafaela Warusch.

En la época de don Juan Roose, la hacienda contó, entre otras estancias, con un comedor, un dormitorio o gabinete, una sala, una antesala, el cuarto de la señorita, que sería el dormitorio de Rafaela Roose Warusch, y el cuarto de pabellones. Las diversas dependencias disfrutaron de un mobiliario en su mayoría de caoba, que hacia 1838 era valorado en 6.245 reales y, a su vez, las habitaciones se adornaron con cuadros, algunos de ellos simples láminas, donde sobre todo abundaban los paisajes, y con grandes espejos. Además la hacienda poseyó todo lo necesario en loza y cristal para el servicio de sus mesas. Esta serie de efectos fueron valorados también por esas mismas fechas en 3.852 reales con 17 maravedíes ${ }^{48}$.

A partir de la adquisición de la finca por parte de don Juan Roose, ésta recibió el nombre de San Rafael, aunque cuando la finca se encuentra en poder de sus descendientes será nombrada tanto San Rafael como de La Cónsula, nombre que quizás adoptara posteriormente por ser la denominación que popularmente recibía la misma y que, hacia los años cincuenta de siglo XIX, ya se tenía como otro de sus nombres. También documentos consultados en 1850 nos indican que la hacienda fue conocida por algunos como la hacienda del Cura, posiblemente por haber pasado por manos de dos presbíteros a lo largo del siglo XVIII ${ }^{49}$.

Toda la hacienda estuvo en poder de don Juan Roose hasta producirse su fallecimiento el 7 de octubre de 1837. Posteriormente pasó a su esposa e hijos y, más tarde, tras fallecer doña Rafaela Warusch, el 28 de agosto de 1849, pasó a sus dos hijos (Enrique y Rafaela) y a su nieta, Rafaela Roose y Sus. En 1839 se realizó el reparto de bienes de don Juan Roose y, entre ellos, la hacienda de San Rafael que con su huerta, casa de recreo y demás pertenencias fue valorada en 637.828 reales, 517.946 reales de vellón sería el valor de la casa de recreo y 119.882 el de la hacienda y huertas. Fue durante estas fechas cuando se produjo la excursión campestre que nos fue relatada por el escritor Ildefonso Marzo en la revista El Guadalhorce:

47. A.H.P.M.: Escribanía de don Francisco Piñón y Tolosa, 1856, leg. 5016, Venta Real Don Enrique Heredia y Livermore contra Don Enrique Roose y Warusch, su hermana y sobrina, fol. 714.

48. A.H.P.M.: Escribanía de don Francisco Mª Piñón, 1839, leg. 4053, Liquidación, cuenta y partición a los bienes y efectos quedados por muerte de Don Juan Roose y Kupckovius, fol. $418 \mathrm{v}$.

49. A.H.P.M.: Escribanía de don Francisco Ma Piñón, leg. 4065, 1850, Liquidación, cuenta y partición de los bienes y efectos quedados por muerte de doña Rafaela Warusch, fol. 1030. 
Después de haber visto El Retiro, su célebre juego de aguas y sus alegres corredores, no permitiendo la consigna del conserje detenerse para comer, prosíguese a sentar los reales en esa calle de altos árboles que sirve de vestíbulo a la Hacienda San Rafael. Esta magnífica casa de campo, propiedad de la familia del Cónsul de Prusia, tiene una elegante arquitectura y una muy bella situación. Desde su amplia galería se disfrutan hermosas vistas sobre la vega y la ciudad... ${ }^{50}$

Pero esta hacienda supuso para la familia Roose una continua carga, dados los numerosos gastos que les ocasionaba, y que para nada podían atenderse con lo que sus huertas producían. De hecho los beneficios de las huertas no eran ni siquiera suficientes para el pago de los diversos encargados de los cultivos, que venían a cobrar unos 560 reales anuales. El principal encargado de sostener la hacienda fue Enrique Roose, comerciante y Cónsul de Prusia, al igual que su padre, quien inicialmente intentó aliviar la situación arrendando parte de la finca.

\subsubsection{El nuevo propietario, Enrique Heredia Livermore:}

En 1856 la casa de recreo necesitaba de urgentes reparaciones para su adecuada conservación, cuyo importe podía ascender aproximadamente a unos 20.000 o 24.000 reales. Don Enrique Roose, como representante de su sobrina, doña Rafaela Roose y Sus, que era aun menor de edad, consideró que la posesión de la hacienda le reportaba a la misma muchos más perjuicios que intereses, ya que el mantenimiento y las actividades de entretenimiento obligaban a continuos desembolsos. Por estos motivos pidió autorización judicial para poder vender en pública subasta la parte que correspondía a su sobrina e invertir el dinero que obtuviese en la adquisición de fincas urbanas o para préstamos. La petición fue aceptada el 4 de septiembre de 1856 y poco después, el 11 de octubre, se subastó la parte de la hacienda correspondiente a la joven, siendo adquirida por don Enrique Guerrero, quien actuaba por encargo de don Enrique Heredia Livermore ${ }^{51}$, en la cantidad de 75.000 reales pagados al contado. En esos momentos la totalidad de la finca había sido apreciada en 394.600 reales y constaba de 11 fanegas y un tercio de otra de terreno.

Posteriormente, tanto doña Rafaela Roose Warusch como su hermano don Enrique, por las mismas causas ya expuestas, consideraron que les era más beneficioso vender sus respectivas partes de la hacienda por lo que se las

50. MARZO, I.: "La Hacienda de San Rafael ó una comida en el Campo", El Guadalhorce 28, 15 de septiembre de 1839. Recorte en (A)rchivo (D)íaz de (E)scovar., Caja 100, 6-4.

51. RAMOS FRENDO, E. M.: "Revival y eclecticismo en las colecciones decimonónicas: Enrique Heredia Livermore y sus bienes artísticos”, Boletín de Arte 23, 2002, 305-23. 
ofrecieron también a don Enrique Heredia Livermore. Don Enrique aceptó, pasando a sus manos, de este modo, la totalidad de la hacienda. La hacienda fue valorada en 400.000 reales.

Enrique residió en Málaga, donde se dedicaba a actividades comerciales, hasta que más tarde trasladó su residencia habitual a Madrid, concretamente a un hotel en el $\mathrm{n}^{\circ} 24$ del Paseo de la Castellana, inmueble que había comprado a su tío político don José de Salamanca y Mayol ${ }^{52}$, el 17 de abril de 1877. Enrique Heredia, al igual que el resto de sus hermanos poseyó una importante colección de piezas de arte: cuadros, esculturas, cerámicas, muebles antiguos, platería, tapices, abanicos, etc. Sobre todo destacan entre las obras pictóricas piezas de: Jacopo Bassano, el Greco, José Antolínez, Mateo Cerezo, Bartolomé Pérez, Pedro de Orrente, Jacinto de Mendoza, Goya, Rafael Mengs, Luis Meléndez, Fleury-Richard, José Vallejo, Vicente López, Manuel Cabral y Aguado-Bejarano y Eduardo Cano de la Peña. Es muy posible que parte de estas obras de arte adornaran algunas de las salas de esta casa de recreo ${ }^{53}$. De hecho, los cronistas malagueños indicaban que junto a otras casas de campo, la de Enrique Heredia era de las que "merecen una visita...por la riqueza de las habitaciones" (posiblemente debida al mobiliario y piezas artísticas que las decoraban $)^{54}$.

Enrique Heredia amplió la hacienda con cuatro fanegas de tierra, plantadas de viñas y almendros que adquirió a doña Rafael Roose Warusch. Se ubicaban en el partido de la Fuente de las Doncellas de Churriana y sus límites estaban rodeados de cipreses y otros árboles. El citado terreno había sido adquirido por don Luis de Torres, vecino de Churriana, al Ayuntamiento de Málaga, quien posteriormente, el 16 de diciembre de 1817, los vendió a doña Rafaela Velasco por la cantidad de 4.700 reales. Esta señora, a su vez, donó dicho predio rústico a doña Rafaela Roose Warusch, la cual con fecha 29 de octubre de 1856 la vendía a Enrique Heredia por 10.000 reales, quien deseaba agregar estos terrenos a la recién adquirida hacienda de San Rafae $^{55}$. Por lo tanto, tras esta nueva adquisición, la totalidad de la hacienda de San Rafael pasó a constar de 15 fanegas y un tercio de otra de terreno. Algunas de las especies botánicas de La Concepción también se encuentran

52. Este ilustre coleccionista y hombre de negocios, don José de Salamanca y Mayol estaba casado con doña Petronila Livermore Salas, hermana de Isabel Livermore Salas, la madre de Enrique Heredia.

53. RAMOS FRENDO, E. M.: "Revival y eclecticismo...op. cit.. Aquí podemos conocer esa heterogénea colección de obras de arte.

54. MUÑOZ CERISOLA, N.: Guía General de Andalucía y Extremadura, Málaga 1879, 386.

55. A.H.P.M.: Escribanía de don Francisco Piñón y Tolosa, 1856, leg. 5016, Venta Real: Don Enrique Heredia Livermore contra Doña Rafaela Roose Warusch, fols. 734-741v. 
en La Cónsula ${ }^{56}$ y no existían en la época de la familia Roose, razón que nos lleva a pensar en la posibilidad de intercambios entre ambas haciendas y a suponer que la mayor parte de las plantas y árboles tropicales de La Cónsula, que hoy observamos y que en la segunda mitad del siglo XIX le daban fama, datan de la época de Enrique Heredia Livermore ${ }^{57}$.

Mientras la hacienda estuvo en manos de la familia Roose sus terrenos estuvieron plantados principalmente de arboles frutales (naranjos, granados, albaricoques, higueras, limoneros, ciruelos, manzanos, sidras, chirimoyos, membrillos, perales, almendros, moreras, parras, caña dulce, etc.) y otros tipos de árboles propios de la zona Mediterránea, (álamos, sauces llorones, chopos, adelfas, laureles, cipreses, olivos, etc.), distribuidos en distintos bancales, que bordeaban caminos que comunicaban las distintas zonas de la hacienda: la casa principal, el jardín de la alberca, los diversos cenadores (cenador de los llorones, cenador de la alberca y cenador de la reja), la gruta, el laberinto, la acequia, el semillero, etc. ${ }^{58}$, mientras que escaseaban las especies exóticas (palmas reales, paraísos y árboles de la vida ${ }^{59}$.

Con Enrique Heredia, en la segunda mitad del siglo XIX, ya se exaltarían "...la hermosura de sus jardines donde las más raras plantas de Europa alterna(ba)n con otras muchas americanas, revelando su íntimo consorcio las escepcionales condiciones de este clima...".

El 15 de octubre de 1884 falleció Enrique Heredia Livermore y un año después, el 3 de enero de 1885, lo hizo su mujer. En el año 1891 se llevó a

56. Para conocer las especies botánicas que hoy posee La Cónsula cfr. CAÑIZO, J. A.: Jardines de...op. cit., 53-56.

57. Algunas de estas especies tropicales que hoy podemos contemplar y que fueron plantadas en época de Enrique Heredia Livermore son: jacarandas, palmeras datileras, arboles del amor, cicas, palmeras reina, palmeras chinas de abanico, bambúes, palmera Butia Capitata, árboles de Júpiter, aguacates, amapola arbustiva de California, Alpinia zerumbet, Chamaedorea, palmeras Washingtonia robusta, Araucaria Bidwillii, Celtis australis, laurel de Indias, yucas finas, palmeras de Canarias, árboles del fuego, platanos de sombra, Cocculus laurifolius del Himalaya, buganvillas, etc. Siempre que nos es posible estamos utilizando el nombre vulgar de la especie y no el genérico.

58. A.H.P.M.: Escribanía de don Francisco Ma Piñón Tolosa, 1839, leg. 4053, Aprecios de la Hacienda de San Rafael perteneciente a los herederos de don Juan Roose padre, fols. 407412.

59. Las Palmas Reales deben de ser las denominadas Oreodoxa regia H,B.K. de Cuba. El documento nos habla de paraísos que podrían referirse a Aves del paraíso o Strelitzia reginae, planta sudafricana o la denominada flor del paraíso que proviene de China y Japón y, finalmente, el árbol de la vida será el Hibiscus mutabilis que es originario de China y de la India y que debe su nombre a los cambios de color que sufren sus flores desde un color blanco hasta amoratado pasando por rosa y rojo. Nos aparece otro árbol denominado árbol del coral y que no identificamos entre las especies tropicales. 
cabo la partición de los bienes del matrimonio ${ }^{60}$. La hacienda de San Rafael, valorada en 53.750 pesetas, pasó a uno de sus hijos, Carlos Heredia Cámara, junto con la mitad de todas las piezas artísticas de Enrique Heredia. A partir de este momento, sí tenemos noticias que nos indican que al menos parte de las obras de arte heredadas de su padre se alojaron en La Cónsula. Concretamente nos remitimos a las palabras de José $\mathrm{M}^{\mathrm{a}}$ Padrón Ruiz quien al hablar sobre esta hacienda, que nos definía como “...otra de las más pintorescas fincas de recreo que hay en los alrededores de nuestra población”, nos exponía que:

El edificio es de lo más elegante que en su género existe; en él hay cuadros y joyas que convierten sus salones en las galerías de una exposición; capiteles, columnas y molduras donde el arte y el buen gusto se disputan la preferencia y no pocos y ricos tapices encargados de engalanar aquella suntuosa mansión ${ }^{61}$.

Por lo tanto, podemos suponer que algunas de las importantes obras pictóricas que poseyó Enrique Heredia, hacia esta fecha, con toda seguridad se encontrarían en la hacienda, ya formando parte de las posesiones de su hijo. Igualmente, como se nos relata, existían numerosos tapices, aunque no se nos indica cuáles, pero es interesante recordar que su padre, dentro de su colección, contó con piezas de gran antigüedad (algunas descritas como de estilo gótico y otras fechadas en los siglos XV y XVI), entre ellas piezas procedentes de Flandes o de Alemania, junto con otras más modernas, entre las que destacaban cuatro tapices de Goya. Por lo tanto, el aspecto de las estancias de la casa de recreo, durante el periodo de la familia Heredia, debió ser de un mayor lujo y esplendor que en épocas anteriores.

Esta es la ligera aproximación que hemos realizado a estas tres villas de recreo que hacia la segunda mitad del siglo XIX estuvieron en manos de miembros de una misma familia hasta que con el siglo XX fueron pasando a manos de nuevos propietarios, pero esa ya sería otra historia. 